\title{
Role of the levonorgestrel intrauterine system in effective contraception
}

\author{
This article was published in the following Dove Press journal: \\ Patient Preference and Adherence \\ 8 August 2013 \\ Number of times this article has been viewed
}

\author{
Abdelhamid M Attia' \\ Magdy M Ibrahim' \\ Ahmed M Abou-Setta ${ }^{2}$ \\ 'Department of Obstetrics and \\ Gynecology, Cairo University, Cairo, \\ Egypt; ${ }^{2}$ George and Fay Yee Centre \\ for Healthcare Innovation, \\ University of Manitoba/Winnipeg \\ Regional Health Authority, \\ Winnipeg, MB, Canada
}

\begin{abstract}
Norgestrel, a synthetic progestin chemically derived from 19-nortestosterone, is six times more potent than progesterone, with variable binding affinity to various steroid receptors. The levonorgestrel-releasing intrauterine system (LNG IUS) provides a long-acting, highly effective, and reversible form of contraception, with a pearl index of 0.18 per 100 women-years. The locally released hormone leads to endometrial concentrations that are 200-800 times those found after daily oral use and a plasma level that is lower than that with other forms of levonorgestrelcontaining contraception. The contraceptive effect of the LNG IUS is achieved mainly through its local suppressive effect on the endometrium, leading to endometrial thinning, glandular atrophy, and stromal decidualization without affecting ovulation. The LNG IUS is generally well tolerated. The main side effects are related to its androgenic activity, which is usually mild and transient, resolving after the first few months. Menstrual abnormalities are also common but well tolerated, and even become desirable (eg, amenorrhea, hypomenorrhea, and oligomenorrhea) with proper counseling of the patient during the choice of the method of contraception. The satisfaction rates after 3 years of insertion are high, reaching between $77 \%$ and $94 \%$. The local effect of the LNG IUS on the endometrium and low rates of systemic adverse effects have led to its use in other conditions rather than contraception, as for the treatment of endometrial hyperplasia, benign menorrhagia, endometriosis, adenomyosis, and uterine fibroids.
\end{abstract}

Keywords: levonorgestrel, intrauterine device, contraception, family planning, Mirena, Skyla

\section{Introduction}

Family planning has been an important part of social development for thousands of years. Safe and effective birth control dates as far back as the time of the ancient Egyptians, who used some of the earliest forms of spermicides and barrier-contraceptive methods. ${ }^{1}$ However, it was not until the second half of the twentieth century that reliable contraceptive methods became commonly available. The purpose of this comprehensive review is to provide an overview of the important issues relating to the use of levonorgestrel (LNG)-medicated intrauterine devices in women for contraception. This review covers a broad range of topics, from the pharmacologic basis and contraceptive action of LNG to the effectiveness and safety of LNG-containing intrauterine systems (IUSs). In addition, the review covers technical aspects, such as timing of insertion and removal and the use of peri-insertion analgesia.

Since their introduction in clinical practice, the use of hormonal combined oral contraceptive pills, containing a higher dose of estrogen and progesterone than what is commonly used today, rapidly spread worldwide. The main mechanism of action of
Correspondence: Ahmed M Abou-Setta George and Fay Yee Center for Healthcare Innovation, University of Manitoba/Winnipeg Regional Health Authority, GH-7/4 - 820 Sherbrook Street, Winnipeg, MB R3A IR9, Canada

$\mathrm{Tel}+\mathrm{I} 2047878707$

Fax +I 2047877567

Email ahmed_abou-setta@umanitoba.ca 
these pills is by suppressing the mid-cycle surge of luteinizing and follicle-stimulating hormones and thereby inhibiting ovulation. ${ }^{2}$ They have a pearl index as low as $0.3 / 100$ womenyears ${ }^{3}$ and typical failure rate of $5 \%$ per year. ${ }^{4}$ As the association between estrogen and serious adverse events, including a higher risk of thromboembolism, became clear, the focus of hormonal contraception became more concentrated on using less estrogen, the search for synthetic alternatives to progesterone, and new delivery methods.

In 2001, the term "progestin" was coined to describe synthetic progestational steroids ${ }^{5}$ and to differentiate them from natural progesterone. Today, progestin-containing contraceptives are becoming more and more popular and come in different forms, including a combined oral contraceptive pill, progestin-only pill, emergency contraceptive pill, subdermal implant, and medicated intrauterine contraceptive device.

The first natural progesterone-releasing IUS (Progestasert) contained $38 \mathrm{mg}$ of progesterone, released at a rate of $65 \mu \mathrm{g}$ daily for 1 year, $^{6}$ and had a failure rate of $2 \% .^{7}$ In 1990 , a new LNG-containing intrauterine system was introduced, quickly replacing the old progesterone-releasing system. Its major advantages included a low dose of LNG (14-20 $\mu \mathrm{g}$ per day), a 5-year life cycle, and decreased menstrual blood loss. ${ }^{8}$ Currently, there are two types of commercially available, US Food and Drug Administration-approved LNG-releasing IUSs. The LNG-20 IUS (Mirena; Bayer, Leverkusen, Germany), contains $52 \mathrm{mg} \mathrm{LNG}$, which is released into the uterine cavity at a constant dose of $20 \mu \mathrm{g}$ per day for 5 years. ${ }^{9}$ A new lower-dose device, the LNG-14 IUS, (Skyla; Bayer), contains $13.5 \mathrm{mg} \mathrm{LNG}$, which is released at a rate of $14 \mu \mathrm{g}$ per day for 3 years. ${ }^{10}$

\section{Pharmacology}

Progestins are synthesized by minor structural changes to progesterone, testosterone, and more recently spironolactone, ${ }^{11}$ which leads to marked changes in the biological activity of the newly synthesized steroid. ${ }^{12}$ LNG (D[-]1-17 $\beta$ hydroxy-17 $\alpha$-ethinyl-13 $\beta$-ethyl-4-gonen-3-one), a synthetic second-generation progestin chemically derived from 19 -nortestosterone, ${ }^{13}$ is six times more potent than progesterone, but also has strong androgenic properties and binding potential to the sex hormone-binding globulin. ${ }^{14}$ It also has variable binding affinity to various human steroid receptors, including glucocorticoid receptors and mineralocorticoid receptors, and minimal binding to estrogen receptors. ${ }^{15}$ Binding of $\mathrm{LNG}$ to receptors other than that of progesterone leads to the commonly observed adverse effects (eg, water retention).

LNG can be administered using a multitude of delivery mechanisms. Oral LNG is rapidly absorbed, circulates bound to albumin and the sex hormone-binding globulin, with only $2.5 \%$ of the circulating hormone unbound. ${ }^{16}$ It is metabolized by hydroxylation at carbons 2 and 16 to produce metabolites that circulate predominantly as sulfates in blood and then excreted as glucuronides in urine. ${ }^{17}$

Locally released $\mathrm{LNG}$, on the other hand, is absorbed into the systemic circulation, reaching a plateau of $100-200 \mathrm{pg} / \mathrm{mL}$ a few weeks after intrauterine insertion. ${ }^{18}$ This plasma level is lower than what is seen with LNG implants, combined oral contraceptive pills, and the minipill, and is not enough to suppress ovulation. ${ }^{8}$ Compared to a typical oral daily dose of $150 \mu \mathrm{g}$, the plasma level with LNG delivered through the LNG-20 IUS is only 4\%-13\% of the levels observed after oral LNG. ${ }^{18}$ More importantly, locally released LNG leads to endometrial concentrations that are 200-800 times those found after daily oral use, while myometrial concentrations are almost identical to that after oral intake. ${ }^{9}$

\section{Mechanism of contraceptive action}

Depending on the method of administration, LNG has several contraceptive properties. While the main mechanism of action of oral LNG is through its suppressive effect on the secretion of hypothalamic gonadotropin-releasing hormone, thereby preventing the mid-cycle luteinizing hormone surge and suppressing ovulation, ${ }^{19}$ the major mechanism of action of the LNG IUS is through its local suppressive effect on the endometrium, including glandular atrophy and decidualization of the stroma. ${ }^{20}$

LNG also causes a downregulation of the local endometrial estrogen receptors, rendering them less responsive to circulating estradiol, ${ }^{21}$ and ultimately leading to endometrial thinning. ${ }^{22}$ Furthermore, LNG helps the expression of glycodelin A in the endometrium between days 6 and 17 of the menstrual cycle. ${ }^{23}$ Glycodelin $\mathrm{A}$ is a protein that prevents binding of sperm to zona pellucida, inhibiting fertilization, and is usually absent in the fertile days of the mid-cycle till the fifth postovulatory day.

Another possible mechanism of action of LNG is by making the cervical mucus thicker, rendering it hostile to sperms. ${ }^{8,24}$ This, combined with its endometrial effect, inhibits sperm mobility and function inside the cervix, uterine body, and fallopian tubes. 


\section{Efficacy, effectiveness, and cost- effectiveness}

Most of the evidence on the efficacy and effectiveness of the LNG IUSs has come from studies on the LNG-20 IUS, as the LNG-14 system is relatively new. LNG IUSs have been shown to be an effective, reliable, and reversible method of contraception, with a pearl index of 0.18 per 100 womenyears. Randomized clinical trials testing its efficacy compared with other types of intrauterine devices, and combined oral contraceptive pills, showed that the cumulative failure rate for the LNG IUS was better than with traditional copperreleasing intrauterine devices ( 1.1 vs 1.4 per 100 women). ${ }^{22,25}$ Its effectiveness in everyday practice was reported to allow a gross cumulative pregnancy rate of one woman per 100 at 5 years, ${ }^{26}$ which is excellent compared to other forms of reversible contraception.

A Cochrane review examining the efficacy of the LNG IUS compared to other methods of contraception concluded that there is no significant difference in pregnancy rates between users of the IUS, copper intrauterine devices, or combined oral contraceptive pills. ${ }^{27}$

Cost-effectiveness is another important factor in the choice of suitable contraception, especially in areas with limited health budgets. Using a constructed Markov model, Chiou and colleagues ${ }^{28}$ compared the cost-effectiveness of nine methods of contraception. After 5 years of use, the comparative effectiveness of the LNG IUS was the highest (98.9\%) of all reversible contraceptive methods. The costeffectiveness analysis also showed the superiority of the LNG IUS over all other reviewed methods.

For the duration of contraceptive efficacy, the LNG-20 IUS is licensed for a duration of 5 years of use, while the LNG-14 IUS is only licensed for 3 years.

\section{Timing of insertion}

IUSs can be inserted within 7 days of the onset of menstruation or at any time during the menstrual cycle, but care should be taken to be sure that the woman is not in her early weeks of pregnancy. If there is any doubt about the woman being pregnant, as in cases of amenorrhea or in women who were not compliant with previous forms of contraception, a pregnancy test should be obtained at least 2 weeks after her last unprotected intercourse..$^{29}$ For women who are switching from another method of contraception, intrauterine insertion should be done before discontinuing the previous method, so as to maintain contraceptive cover. Otherwise, a backup method of contraception should be used for the first 7 days after IUS insertion. ${ }^{29}$
For postpartum women, immediate postpartum insertion has not been studied extensively and is not recommended. ${ }^{30,31}$ However, after a complete abortion and in the absence of sepsis or bleeding, insertion can be performed immediately. ${ }^{29}$

\section{Analgesia}

Common to all intrauterine device insertions, insertion of the LNG IUS should be pain-free, with only minor discomfort in some women. Nulliparas, women requiring cervical dilation or with a history of prior painful intrauterine device insertion may benefit from preinsertion analgesia. Evidence from randomized trials shows that preprocedural analgesia with oral nonsteroidal anti-inflammatory drugs, with or without cotreatment with misoprostol, does not significantly reduce pain associated with insertion, ${ }^{32}$ and trials on the use of topical cervical analgesia (eg, topical lidocaine) are conflicting. ${ }^{33-35}$ Nerve block (eg, paracervical block) using 10-20 $\mathrm{mL}$ of $1 \%$ lidocaine injected to a depth of approximately $1 \mathrm{~cm}$ should also be considered when analgesia is required.

\section{Proper insertion procedure}

The fundal position in the uterine cavity is particularly important, as good fundic placement provides excellent protection against pregnancy, a low rate of removal for bleeding, and the total suppression of endometrial growth. Special emphasis should be given to training in the correct insertion technique, as it is different from standard intrauterine devices.

In cases where there is difficulty on insertion, the cervix should be gently dilated with a lacrimal duct probe or cervical dilator; analgesia/local anesthesia may be used on a case-by-case basis. If resistance is still encountered after mild dilatation, the provider should reassess the uterine position and consider the possibility of obstructive lesions. In such cases, insertion may be reattempted under ultrasound guidance. For women with fibroids, especially submucosal ones, insertion under ultrasound guidance may be useful to ensure proper fundic placement of the device. If ultrasound was not used during the procedure itself, prompt postprocedure ultrasonography is useful to confirm correct placement in any woman in whom insertion was difficult. ${ }^{29}$

Despite limited data, clinicians may consider drugs that soften the cervix, and thereby also reduce insertion-related pain. Intracervical nitroprusside ge ${ }^{36}$ and vaginal, oral, or sublingual misoprosto ${ }^{37-43}$ have been described with conflicting results. 


\section{Prevention of infection}

Although the risk of pelvic inflammatory disease is reported to be low $(0.5 \%)$ in new users, ${ }^{44}$ screening potential candidates for sexually transmitted disease and excluding cervicitis or vaginitis are important steps before insertion, and women should be made aware of the signs and symptoms. Routine screening for gonorrhea and chlamydia in this population is controversial; however, selective screening appears to be an acceptable alternative in high-risk populations. ${ }^{45}$

If a pelvic infection is identified during screening, especially gonorrhea or chlamydia, it should be treated prior to insertion and intrauterine placement postponed until the infection resolves. In the meantime, another form of contraception should be used.

In the case of pelvic infection detected after insertion, the intrauterine device does not need to be removed per se, but rather treatment should be started promptly and the woman followed up quarterly to confirm resolution of the infection and the absence of reinfection. ${ }^{29}$ If infections are not resolving with treatment, then temporary removal of the intrauterine device should be considered, as well as counseling on possible reasons for the lack of improvement (eg, lack of compliance with treatment, repeated infections).

In general, antibiotic prophylaxis provides no benefit ${ }^{46}$ and is not recommended..$^{45}$ Additionally, the American Heart Association does not recommend endocarditis prophylaxis for intrauterine device insertion in the absence of a pelvic infection. ${ }^{47,48}$

\section{Side-effect profile}

The LNG IUS is generally well tolerated, and side effects can be divided into short-term, long-term, and adverse effects specific to LNG or common to intrauterine devices in general.

\section{Short-term side effects}

Mild lower abdominal and back pain is common after insertion, and occurs in roughly half of women with new insertions ${ }^{49}$ In addition, in the first few months of use, women may notice side effects related to the androgenic activity of LNG (eg, nausea, headache, breast tenderness, depression, and acne). ${ }^{22,49-51}$ These are usually mild, transient, and decrease over time..$^{24,52}$ Menstrual disturbances are also common during the first 3 months of use. ${ }^{53-57}$

\section{Long-term side effects}

Over time, bleeding frequency begins to decrease, eventually leading to hypomenorrhea and amenorrhea in many women. ${ }^{49,58,59}$ As previously discussed, this is due to endometrial thinning and atrophy due to the prolonged effect of $\mathrm{LNG}$ on the endometrium.

Unlike oral hormonal therapies, LNG IUSs have not been linked to hypertension, ${ }^{60}$ weight gain, ${ }^{22}$ hyperglycemia, ${ }^{61}$ hyperlipidemia/hypercholesterolemia, ${ }^{62}$ reduced bone mineral density, ${ }^{63,64}$ or increased metabolic cardiovascular and inflammatory parameters. ${ }^{65}$ There is also no evidence of increased risk of venous thromboembolism, ${ }^{66}$ stroke, or myocardial infarction. ${ }^{67}$

Functional ovarian cysts are commonly seen in women using the LNG IUS, with an incidence that varies between $5 \%$ and $30 \%$, but in the majority of women the enlarged follicles are asymptomatic, being diagnosed on routine ultrasonography, and resolve spontaneously within the first few months following diagnosis. ${ }^{26,52,68-70}$

Due to the effect of progestin on tubal motility and increased mucus viscosity, an association between progestinbased contraceptives and tubal ectopic pregnancy has long been postulated. Postmarketing surveillance and randomized trials have put the risk at $0.2-0.4$ per 1,000 women-years, ${ }^{9,71}$ which is lower than that seen with other commonly used intrauterine devices. ${ }^{22}$

Although guidelines state that the use of the LNG IUS is contraindicated in women with breast cancer, studies have not found an increased risk of breast cancer in LNG IUS users. $^{72-74}$

\section{Side effects common to intrauterine devices}

As previously noted, pelvic inflammatory disease is not common with intrauterine device users, and routine screening or prophylactic antibiotics are not recommended. Directed screening of women at high risk of infection is a more appropriate strategy. ${ }^{1,75}$ With LNG IUSs, the incidence of pelvic inflammatory disease is lower than with copper intrauterine devices ${ }^{22,76,77}$ and similar to oral contraceptive users. ${ }^{49}$

Uterine perforation is a potentially serious complication of any intrauterine manipulation. Fortunately, with proper training on the technique of LNG-IUS insertion, uterine perforation is a rarely seen phenomenon. Studies have shown that the rate of uterine perforation with intrauterine device insertion is around $0.44-0.53$ per 1,000 insertions. ${ }^{78}$ Risk factors for perforation include an inexperienced clinician, stenosed cervix, immobile and retroverted uterus, ${ }^{29}$ and postpartum insertion. ${ }^{79,80}$

The risk of intrauterine device expulsion is around 5\%, and occurs mainly in the first 3 months after insertion. 
The cumulative expulsion rate of the LNG IUS after 5 years was reported to be under $6 \%$, which is similar to other types of intrauterine devices. ${ }^{22,81}$ Nulliparas, women with severe dysmenorrhea, and insertions placed immediately postpartum or postabortion are at increased risk of expulsion..$^{82,83}$

\section{Side effects associated with the new lower-dose intrauterine system}

The available information about the side effects of the newly approved lower-dose LNG-14 IUS is sparse. When compared simultaneously, as the dose of LNG increased, the total days of bleeding and spotting decreased, and amenorrhea rates at 3 years increased ${ }^{84}$ Ovarian cyst formation was also shown to be dose-dependent. Other side effects were similar between LNG-releasing hormone systems.

\section{Removal of the levonorgestrel intrauterine system}

Unless contraindicated, removal can be done at any time during the menstrual cycle. Removal is rarely described as painful, even though women may feel some pain and discomfort during the removal. ${ }^{52}$ As with insertion, antibiotic prophylaxis, culture, or pathologic examination is unnecessary for routine removals. ${ }^{29}$ The choice to remove the intrauterine device may be based on many factors, including but not limited to the desire to become pregnant, abnormal bleeding or amenorrhea, unresolved pelvic infection, and at the discretion of the attending physician. Even if for no other reason, the device should be routinely replaced every 3-5 years (depending on the product life cycle) or when the woman reaches menopause or no longer desires this form of contraception.

If a new device is planned to be inserted immediately following the removal of the current IUS, then no backup contraceptive is needed. On the other hand, if the woman is switching to another contraceptive method, depending on the contraception to be used, she may need to consider using backup contraception. For example, if a woman had unprotected intercourse within 3-5 days of removal and her new method requires backup contraception for the first week of use, then she may need oral emergency contraception as additional protection.

\section{Counseling}

In general, the LNG IUS is well accepted by women and has a favorable efficacy:safety ratio. ${ }^{53}$ The most common side effects reported that lead to discontinuation are related to changes in menstrual patterns, mainly amenorrhea, hypomenorrhea, and breakthrough bleeding. ${ }^{53}$
Experience has shown that training on how to counsel prospective recipients is essential prior to insertion. Women need to be informed about the possible changes to their menstrual bleeding patterns, particularly in the first few months of use, and the possibility that menstruation will stop altogether (eg, hypomenorrhea or amenorrhea). ${ }^{85}$ While amenorrhea may be mistaken for pregnancy or menopause, unexpected bleeding may be worrisome, and women may be unsure if this is due to the use of LNG, a sign of pregnancy, or something else.

Women should be made aware that the average number of bleeding or spotting days may vary from their normal routine, and provided with a clear explanation why amenorrhea may occur. If women are emotionally prepared for the changes they may be seeing after IUS insertion, they are less likely to have anxiety about unexpected bleeding or amenorrhea. ${ }^{50}$ Furthermore, proper counseling should improve compliance, by helping to avoid premature unnecessary removal for nonmedical reasons. ${ }^{60,86}$

The counseling topics that have shown the greatest impact on user satisfaction are issues surrounding amenorrhea, abnormal or untimely bleeding, occurrence of pelvic inflammatory diseases, hormonal adverse effects, and the possibility of pregnancy. ${ }^{87}$ As amenorrhea caused by the high local concentrations of $\mathrm{LNG}$ in the endometrium is more prevalent in long-term users, counseling is important with repeated, long-term use of the LNG IUS. ${ }^{88}$ Also, cultural considerations and provider attitudes can lead to different responses to the occurrence of amenorrhea.

In summary, with proper counseling, women using the LNG IUS will have a better understanding of the expected physiological changes to their menstrual cycles, and a more positive attitude towards amenorrhea. A big part of this change in attitudes towards amenorrhea with LNG is the direct effect of proper patient counseling.

\section{Acceptability, user satisfaction, and quality of life}

While the efficacy of contraceptives is measured by pregnancy (or failure) rates, their acceptability is evaluated by the continuation rate. As the LNG-14 IUS is relatively new to the market, little is known about compliance rates, acceptability, user satisfaction, or quality of life with this new lower-dose LNG IUS. Even so, there is a body of evidence to suggest that the LNG-20 IUS is well accepted by women.

In nulliparous women, the LNG-20 IUS and combined oral contraceptive pills have been shown to have similar 1 -year continuation rates, but the overall satisfaction rate was 
shown to be significantly higher with LNG-20 use. ${ }^{49}$ LNG-20 was also associated with significantly less dysmenorrhea and intermenstrual bleeding and spotting, and significantly fewer total bleeding days. On the other hand, LNG-20 was accompanied by fewer regular cycles and more cases of amenorrhea. In parous women, the LNG-20 IUS has been demonstrated to achieve an approximate $80 \%$ annual continuation rate, while discontinuation is mostly related to menstrual disturbances, similar to copper intrauterine devices. ${ }^{22,25,89}$

In addition, satisfaction rates with the LNG IUS seem to increase over time ( $69 \%$ at 6 months and $77 \%$ at 36 months). ${ }^{69}$ A postmarketing survey conducted across Europe showed an overall satisfaction rate of $79 \% .^{90}$ A recent Spanish survey in women using the IUS for at least 2 years revealed a satisfaction rate of $94 \% .{ }^{91}$ Even so, there are very limited data regarding the effects of using the LNG IUS on quality of life in women using it mainly for contraception. ${ }^{52}$

\section{Indications for use other than contraception}

The success of the LNG IUS in providing locally released progestins without causing marked systemic adverse effects has led to its use in other pelvic conditions, regardless of the need for contraception. LNG IUS use has been proposed for atypical endometrial hyperplasia, ${ }^{92}$ heavy menstrual bleeding, ${ }^{93}$ endometriosis and adenomyosis, ${ }^{94}$ and uterine fibroids. ${ }^{95}$

Endometrial hyperplasia has been associated with the development of endometrial carcinoma, one of the most common gynecologic malignancies worldwide. Even though inducing endometrial atrophy by localized administration of LNG offers a safe and effective fertility-sparing option, this theory has only recently been tested in randomized trials. ${ }^{92}$ Treatment success was higher for LNG-releasing intrauterine devices compared against oral progestin administration, ${ }^{96-98}$ and as prophylaxis against developing endometrial pathology in women receiving tamoxifen. ${ }^{99}$

Levonorgestrel is a natural choice for treating heavy menstrual bleeding by thinning the endometrial lining. A recent Cochrane review ${ }^{93}$ reported that the LNG IUS is more effective than oral contraceptive pills and associated with more patient satisfaction and continuity of treatment.

Endometriosis, the aberrant growth of endometrial tissue outside the uterine cavity, has also been shown to be suppressed by the pelvic release of LNG. A recently updated Cochrane review ${ }^{94}$ revealed that there was limited, but consistent, evidence showing that postoperative LNG IUS use reduces the recurrence of painful periods in women with endometriosis.
Finally, in the management of fibroids, LNG IUSs have been reported to reduce the amount of menstrual bleeding, while oral progestins were ineffective. ${ }^{95}$ The Cochrane review authors noted that even though this evidence is suggestive of a clinically important effect, more evidence is needed to confirm the results of their analyses.

\section{Conclusion}

LNG locally released in the endometrial cavity is both a safe and reliable method of contraception. It benefits from the atrophic effect of progestins on the endometrium, while not suffering the systemic side effects seen with other methods of progestin administration. Even so, as it causes marked endometrial atrophy leading to menstrual disturbances, hypomenorrhea, and amenorrhea, patient counseling prior to insertion is vital for improving compliance and reducing anxiety accompanied with unexpected changes in a woman's menstrual pattern. Furthermore, clinician training is required on the insertion of the IUS, indications and types of analgesics used during insertion, and patient counseling. With the introduction of a lower-dose version of the traditional LNG IUS, it is expected that patient compliance will increase as side effects decrease. Finally, contraception is only one indication where local administration of LNG seems to be beneficial, and therefore its use may increase over time, not only for its contraceptive properties, but for managing other pelvic conditions.

\section{Disclosure}

The authors report no conflicts of interest in this work.

\section{References}

1. Grimes DA. Intrauterine device and upper-genital-tract infection. Lancet. 2000;356(9234):1013-1019.

2. Sondheimer SJ. Oral contraceptives: mechanism of action, dosing, safety, and efficacy. Cutis. 2008;81(Suppl 1):19-22.

3. World Health Organization. Medical Eligibility Criteria for Contraceptive Use. 4th ed. Geneva: WHO; 2010.

4. Trussell J, Vaughan B. Contraceptive failure, method-related discontinuation and resumption of use: results from the 1995 National Survey of Family Growth. Fam Plann Perspect. 1999;31(2):64-72, 93.

5. Stanczyk FZ, Henzl MR. Use of the name "Progestin". Contraception. 2001;64(1):1-2.

6. Rose S, Chaudhari A, Peterson CM. Mirena (levonorgestrel intrauterine system): a successful novel drug delivery option in contraception. Adv Drug Deliv Rev. 2009;61(10):808-812.

7. Samra-Latif OM. Contraception. 2013. Available from: http:// emedicine.medscape.com/article/258507-overview. Accessed July 17, 2013.

8. Luukkainen T, Lahteenmaki P, Toivonen J. Levonorgestrel-releasing intrauterine device. Ann Med. 1990;22(2):85-90.

9. Lahteenmaki P, Rauramo I, Backman T. The levonorgestrel intrauterine system in contraception. Steroids. 2000;65(10-11):693-697.

10. Dean G, Goldberg AB. Overview of intrauterine contraception. 2013. Available from: http://www.uptodate.com/contents/overview-ofintrauterine-contraception?source=see_link. Accessed July 19, 2013. 
11. Benagiano G, Primiero FM, Farris M. Clinical profile of contraceptive progestins. Eur J Contracept Reprod Health Care. 2004;9(3): 182-193.

12. Sitruk-Ware R. New progestagens for contraceptive use. Hum Reprod Update. 2006;12(2):169-178.

13. Benagiano G, Carrara S, Filippi V. Safety, efficacy and patient satisfaction with continuous daily administration of levonorgestrel/ ethinylestradiol oral contraceptives. Patient Prefer Adherence. 2009;3: 131-143.

14. Rowlands S. Newer progestogens. J Fam Plann Reprod Health Care. 2003;29(1):13-16.

15. Sitruk-Ware R. New progestogens: a review of their effects in perimenopausal and postmenopausal women. Drugs Aging. 2004;21(13): 865-883.

16. Schindler AE, Campagnoli C, Druckmann R, et al. Classification and pharmacology of progestins. Maturitas. 2003;46 Suppl 1: S7-S16.

17. Stanczyk FZ, Roy S. Metabolism of levonorgestrel, norethindrone, and structurally related contraceptive steroids. Contraception. 1990;42(1):67-96.

18. Nilsson CG, Lahteenmaki PL, Luukkainen T, Robertson DN. Sustained intrauterine release of levonorgestrel over five years. Fertil Steril. 1986;45(6):805-807.

19. Klaisle CM, Wysocki S. Innovations in contraception: the Norplant system. NAACOGS Clin Issu Perinat Womens Health Nurs. 1992;3(2):267-279.

20. Silverberg SG, Haukkamaa M, Arko H, Nilsson CG, Luukkainen T. Endometrial morphology during long-term use of levonorgestrelreleasing intrauterine devices. Int J Gynecol Pathol. 1986;5(3): 235-241.

21. Critchley HO, Wang H, Kelly RW, Gebbie AE, Glasier AF. Progestin receptor isoforms and prostaglandin dehydrogenase in the endometrium of women using a levonorgestrel-releasing intrauterine system. Hum Reprod. 1998;13(5):1210-1217.

22. Andersson K, Odlind V, Rybo G. Levonorgestrel-releasing and copperreleasing (Nova T) IUDs during five years of use: a randomized comparative trial. Contraception. 1994;49(1):56-72.

23. Ortiz ME, Croxatto HB. Copper-T intrauterine device and levonorgestrel intrauterine system: biological bases of their mechanism of action. Contraception. 2007;75(Suppl 6):S16-S30.

24. Guillebaud J. The levonorgestrel intrauterine system: a clinical perspective from the UK. Ann N Y Acad Sci. 2003;997:185-193.

25. Sivin I, Stern J, Coutinho E, et al. Prolonged intrauterine contraception: a seven-year randomized study of the levonorgestrel $20 \mathrm{mcg} / \mathrm{day}$ (LNg 20) and the Copper T380 Ag IUDS. Contraception. 1991;44(5): 473-480.

26. Cox M, Tripp J, Blacksell S. Clinical performance of the levonorgestrel intrauterine system in routine use by the UK Family Planning and Reproductive Health Research Network: 5-year report. J Fam Plann Reprod Health Care. 2002;28(2):73-77.

27. French R, Van Vliet H, Cowan F, et al. Hormonally impregnated intrauterine systems (IUSs) versus other forms of reversible contraceptives as effective methods of preventing pregnancy. Cochrane Database Syst Rev. 2004;(3):CD001776.

28. Chiou CF, Trussell J, Reyes E, et al. Economic analysis of contraceptives for women. Contraception. 2003;68(1):3-10.

29. Carusi DA, Goldberg AB. Insertion and removal of an intrauterine contraceptive device. 2013. Available from: http://www.uptodate. com/contents/insertion-and-removal-of-an-intrauterine-contraceptivedevice?source=see_link. Accessed July 19, 2013.

30. Chen BA, Reeves MF, Hayes JL, Hohmann HL, Perriera LK, Creinin MD. Postplacental or delayed insertion of the levonorgestrel intrauterine device after vaginal delivery: a randomized controlled trial. Obstet Gynecol. 2010;116(5):1079-1087.

31. Hayes JL, Cwiak C, Goedken P, Zieman M. A pilot clinical trial of ultrasound-guided postplacental insertion of a levonorgestrel intrauterine device. Contraception. 2007;76(4):292-296.
32. Allen RH, Bartz D, Grimes DA, Hubacher D, O'Brien P. Interventions for pain with intrauterine device insertion. Cochrane Database Syst Rev. 2009;(3):CD007373.

33. Maguire K, Davis A, Rosario Tejeda L, Westhoff C. Intracervical lidocaine gel for intrauterine device insertion: a randomized controlled trial. Contraception. 2012;86(3):214-219.

34. McNicholas CP, Madden T, Zhao Q, Secura G, Allsworth JE, Peipert JF. Cervical lidocaine for IUD insertional pain: a randomized controlled trial. Am J Obstet Gynecol. 2012;207(5):384. e1-e6.

35. Oloto EJ, Bromham DR, Murty JA. Pain and discomfort perception at IUD insertion - effect of short-duration, low-volume, intracervical application of two percent lignocaine gel (Instillagel) - a preliminary study. Br J Fam Plann. 1997;22(4):177-180.

36. Bednarek PH, Micks EA, Edelman AB, Li H, Jensen JT. The effect of nitroprusside on IUD insertion experience in nulliparous women: a pilot study. Contraception. 2013;87(4):421-425.

37. Dijkhuizen K, Dekkers OM, Holleboom CA, et al. Vaginal misoprostol prior to insertion of an intrauterine device: an RCT. Hum Reprod. 2011;26(2):323-329.

38. Edelman AB, Schaefer E, Olson A, et al. Effects of prophylactic misoprostol administration prior to intrauterine device insertion in nulliparous women. Contraception. 2011;84(3):234-239.

39. Heikinheimo O, Inki P, Kunz M, et al. Double-blind, randomized, placebo-controlled study on the effect of misoprostol on ease of consecutive insertion of the levonorgestrel-releasing intrauterine system. Contraception. 2010;81(6):481-486.

40. Li YT, Kuo TC, Kuan LC, Chu YC. Cervical softening with vaginal misoprostol before intrauterine device insertion. Int J Gynaecol Obstet. 2005;89(1):67-68

41. Saav I, Aronsson A, Marions L, Stephansson O, GemzellDanielsson K. Cervical priming with sublingual misoprostol prior to insertion of an intrauterine device in nulliparous women: a randomized controlled trial. Hum Reprod. 2007;22(10): 2647-2652.

42. Swenson C, Turok DK, Ward K, Jacobson JC, Dermish A. Self-administered misoprostol or placebo before intrauterine device insertion in nulliparous women: a randomized controlled trial. Obstet Gynecol. 2012;120(2 Pt 1):341-347.

43. Scavuzzi A, Souza AS, Costa AA, Amorim MM. Misoprostol prior to inserting an intrauterine device in nulligravidas: a randomized clinical trial. Hum Reprod. 2013;28(8):2118-2125.

44. Sufrin CB, Postlethwaite D, Armstrong MA, Merchant M, Wendt JM, Steinauer JE. Neisseria gonorrhea and Chlamydia trachomatis screening at intrauterine device insertion and pelvic inflammatory disease. Obstet Gynecol. 2012;120(6):1314-1321.

45. American College of Obstetricians and Gynecologists. ACOG Practice Bulletin No 121: Long-acting reversible contraception: implants and intrauterine devices. Obstet Gynecol. 2011;118(1): 184-196.

46. Grimes DA, Schulz KF. Antibiotic prophylaxis for intrauterine contraceptive device insertion. Cochrane Database Syst Rev. 2001;(2):CD001327.

47. Nishimura RA, Carabello BA, Faxon DP, et al. ACC/AHA 2008 guideline update on valvular heart disease: focused update on infective endocarditis: a report of the American College of Cardiology/ American Heart Association Task Force on Practice Guidelines: endorsed by the Society of Cardiovascular Anesthesiologists, Society for Cardiovascular Angiography and Interventions, and Society of Thoracic Surgeons. Circulation. 2008;118(8):887-896.

48. Wilson W, Taubert KA, Gewitz M, et al. Prevention of infective endocarditis: guidelines from the American Heart Association: a guideline from the American Heart Association Rheumatic Fever, Endocarditis, and Kawasaki Disease Committee, Council on Cardiovascular Disease in the Young, and the Council on Clinical Cardiology, Council on Cardiovascular Surgery and Anesthesia, and the Quality of Care and Outcomes Research Interdisciplinary Working Group. Circulation. 2007;116(15):1736-1754. 
49. Suhonen S, Haukkamaa M, Jakobsson T, Rauramo I. Clinical performance of a levonorgestrel-releasing intrauterine system and oral contraceptives in young nulliparous women: a comparative study. Contraception. 2004;69(5):407-412.

50. Luukkainen T, Toivonen J. Levonorgestrel-releasing IUD as a method of contraception with therapeutic properties. Contraception. 1995;52(5):269-276.

51. Sitruk-Ware R. The levonorgestrel intrauterine system for use in peri- and postmenopausal women. Contraception. 2007;75(Suppl 6): S155-S160.

52. Mansour D. The benefits and risks of using a levonorgestrel-releasing intrauterine system for contraception. Contraception. 2012;85(3): 224-234.

53. Dubuisson JB, Mugnier E. Acceptability of the levonorgestrel-releasing intrauterine system after discontinuation of previous contraception: results of a French clinical study in women aged 35 to 45 years. Contraception. 2002;66(2):121-128.

54. McGavigan CJ, Dockery P, Metaxa-Mariatou V, et al. Hormonally mediated disturbance of angiogenesis in the human endometrium after exposure to intrauterine levonorgestrel. Hum Reprod. 2003; 18(1):77-84.

55. Mosher WD, Martinez GM, Chandra A, Abma JC, Willson SJ. Use of contraception and use of family planning services in the United States: 1982-2002. Adv Data. 2004;(350):1-36.

56. Tewari R, Kay VJ. Compliance and user satisfaction with the intrauterine contraceptive device in Family Planning Service: the results of a survey in Fife, Scotland, August 2004. Eur J Contracept Reprod Health Care. 2006;11(1):28-37.

57. Xiao B, Wu SC, Chong J, Zeng T, Han LH, Luukkainen T. Therapeutic effects of the levonorgestrel-releasing intrauterine system in the treatment of idiopathic menorrhagia. Fertil Steril. 2003;79(4): 963-969.

58. Hidalgo M, Bahamondes L, Perrotti M, Diaz J, Dantas-Monteiro C, Petta C. Bleeding patterns and clinical performance of the levonorgestrel-releasing intrauterine system (Mirena) up to two years. Contraception. 2002;65(2):129-132.

59. Ronnerdag M, Odlind V. Health effects of long-term use of the intrauterine levonorgestrel-releasing system. A follow-up study over 12 years of continuous use. Acta Obstet Gynecol Scand. 1999;78(8): 716-721.

60. Heliovaara-Peippo S, Oksjoki R, Halmesmaki K, et al. The effect of hysterectomy or levonorgestrel-releasing intrauterine system on cardiovascular disease risk factors in menorrhagia patients: a 10-year follow-up of a randomised trial. Maturitas. 2011;69(4):354-358.

61. Rogovskaya S, Rivera R, Grimes DA, et al. Effect of a levonorgestrel intrauterine system on women with type 1 diabetes: a randomized trial. Obstet Gynecol. 2005;105(4):811-815.

62. Graff-Iversen S, Tonstad S. Use of progestogen-only contraceptives/ medications and lipid parameters in women age 40 to 42 years: results of a population-based cross-sectional Norwegian Survey. Contraception. 2002;66(1):7-13.

63. Bahamondes L, Espejo-Arce X, Hidalgo MM, Hidalgo-Regina C, Teatin-Juliato C, Petta CA. A cross-sectional study of the forearm bone density of long-term users of levonorgestrel-releasing intrauterine system. Hum Reprod. 2006;21(5):1316-1319.

64. Bahamondes MV, Monteiro I, Castro S, Espejo-Arce X, Bahamondes L. Prospective study of the forearm bone mineral density of long-term users of the levonorgestrel-releasing intrauterine system. Hum Reprod. 2010;25(5):1158-1164.

65. Morin-Papunen L, Martikainen H, McCarthy MI, et al. Comparison of metabolic and inflammatory outcomes in women who used oral contraceptives and the levonorgestrel-releasing intrauterine device in a general population. Am J Obstet Gynecol. 2008;199(5):529. e1-e529. e10.

66. van Vliet HA, Tchaikovski SN, Rosendaal FR, Rosing J, Helmerhorst FM. The effect of the levonorgestrel-releasing intrauterine system on the resistance to activated protein C (APC). Thromb Haemost. 2009;101(4):691-695.
67. Lidegaard O, Lokkegaard E, Jensen A, Skovlund CW, Keiding N. Thrombotic stroke and myocardial infarction with hormonal contraception. N Engl J Med. 2012;366(24):2257-2266.

68. Jarvela I, Tekay A, Jouppila P. The effect of a levonorgestrelreleasing intrauterine system on uterine artery blood flow, hormone concentrations and ovarian cyst formation in fertile women. Hum Reprod. 1998;13(12):3379-3383.

69. Baldaszti E, Wimmer-Puchinger B, Loschke K. Acceptability of the longterm contraceptive levonorgestrel-releasing intrauterine system (Mirena): a 3-year follow-up study. Contraception. 2003;67(2): 87-91.

70. Inki P, Hurskainen R, Palo P, et al. Comparison of ovarian cyst formation in women using the levonorgestrel-releasing intrauterine system vs hysterectomy. Ultrasound Obstet Gynecol. 2002;20(4):381-385.

71. Berlex Laboratories. Mirena [prescribing information]. 2013. Available from: http://www.berlex.com/html/products/pi/Mirena_PI.pdf. Accessed July 19, 2013.

72. Backman T, Rauramo I, Jaakkola K, et al. Use of the levonorgestrelreleasing intrauterine system and breast cancer. Obstet Gynecol. 2005;106(4):813-817.

73. Dinger J, Bardenheuer K, Minh TD. Levonorgestrel-releasing and copper intrauterine devices and the risk of breast cancer. Contraception. 2011;83(3):211-217.

74. Trinh XB, Tjalma WA, Makar AP, Buytaert G, Weyler J, van Dam PA. Use of the levonorgestrel-releasing intrauterine system in breast cancer patients. Fertil Steril. 2008;90(1):17-22.

75. Farley TM, Rosenberg MJ, Rowe PJ, Chen JH, Meirik O. Intrauterine devices and pelvic inflammatory disease: an international perspective. Lancet. 1992;339(8796):785-788.

76. Sivin I, Stern J. Health during prolonged use of levonorgestrel 20 micrograms/d and the copper TCu $380 \mathrm{Ag}$ intrauterine contraceptive devices: a multicenter study. International Committee for Contraception Research (ICCR). Fertil Steril. 1994;61(1):70-77.

77. Toivonen J, Luukkainen T, Allonen H. Protective effect of intrauterine release of levonorgestrel on pelvic infection: three years' comparative experience of levonorgestrel- and copper-releasing intrauterine devices. Obstet Gynecol. 1991;77(2):261-264.

78. Heinemann K, Barnett C, Dinger J. Risk factors for uterine perforations during IUD insertion: interim results from the EURAS-IUD study. 2011. Available from: http://www.pharmacoepi.org/meetings/27thconf/ presentations/Risk $\% 20$ Factors $\% 20$ for $\% 20$ Uterine $\% 20$ Perforations $\% 20$ during\%20IUD $\% 20$ Insertion- $\% 20$ Interim $\% 20$ Results $\% 20$ from $\% 20$ the\%20EURAS-IUD\%20Study.pdf. Accessed July 19, 2013.

79. Caliskan E, Ozturk N, Dilbaz BO, Dilbaz S. Analysis of risk factors associated with uterine perforation by intrauterine devices. Eur $J$ Contracept Reprod Health Care. 2003;8(3):150-155.

80. Heartwell SF, Schlesselman S. Risk of uterine perforation among users of intrauterine devices. Obstet Gynecol. 1983;61(1):31-36.

81. French RS, Cowan FM, Mansour D, et al. Levonorgestrelreleasing (20 microgram/day) intrauterine systems (Mirena) compared with other methods of reversible contraceptives. BJOG. 2000;107(10):1218-1225

82. Eroglu K, Akkuzu G, Vural G, et al. Comparison of efficacy and complications of IUD insertion in immediate postplacental/early postpartum period with interval period: 1 year follow-up. Contraception. 2006;74(5):376-381.

83. Grimes D, Schulz K, Stanwood N. Immediate postabortal insertion of intrauterine devices. Cochrane Database Syst Rev. 2004;(4):CD001777.

84. Gemzell-Danielsson K, Schellschmidt I, Apter D. A randomized, phase II study describing the efficacy, bleeding profile, and safety of two low-dose levonorgestrel-releasing intrauterine contraceptive systems and Mirena. Fertil Steril. 2012;97(3):616-622. e1-e3.

85. Jensen JT. Contraceptive and therapeutic effects of the levonorgestrel intrauterine system: an overview. Obstet Gynecol Surv. 2005;60(9): 604-612.

86. Davie JE, Walling MR, Mansour DJ, Bromham D, Kishen M, Fowler P. Impact of patient counseling on acceptance of the levonorgestrel implant contraceptive in the United Kingdom. Clin Ther. 1996;18(1):150-159. 
87. Backman T, Huhtala S, Luoto R, Tuominen J, Rauramo I, Koskenvuo M. Advance information improves user satisfaction with the levonorgestrel intrauterine system. Obstet Gynecol. 2002;99(4): 608-613.

88. Inki P. Long-term use of the levonorgestrel-releasing intrauterine system. Contraception. 2007;75(Supp1 6):S161-S166.

89. Sivin I, Alvarez F, Diaz J, et al. Intrauterine contraception with copper and with levonorgestrel: a randomized study of the $\mathrm{TCu} 380 \mathrm{Ag}$ and levonorgestrel $20 \mathrm{mcg} /$ day devices. Contraception. 1984;30(5): 443-456.

90. Cibula D. Women's contraceptive practices and sexual behaviour in Europe. Eur J Contracept Reprod Health Care. 2008;13(4):362-375.

91. García IC, García EV, Rubio MT, et al. Estudio de satisfacción en usuarias españolas del DIU-LNG (Mirena). Rev Iberoam Fertil Reprod Hum. 2009;26(4):335-342.

92. Luo L, Luo B, Zheng Y, Zhang H, Li J, Sidell N. Levonorgestrelreleasing intrauterine system for atypical endometrial hyperplasia. Cochrane Database Syst Rev. 2013;6:CD009458.

93. Lethaby AE, Cooke I, Rees M. Progesterone or progestogen-releasing intrauterine systems for heavy menstrual bleeding. Cochrane Database Syst Rev. 2005;(4):CD002126.

94. Abou-Setta AM, Houston B, Al-Inany HG, Farquhar C. Levonorgestrel-releasing intrauterine device (LNG-IUD) for symptomatic endometriosis following surgery. Cochrane Database Syst Rev. 2013;1:CD005072.
95. Sangkomkamhang US, Lumbiganon P, Laopaiboon M, Mol BW. Progestogens or progestogen-releasing intrauterine systems for uterine fibroids. Cochrane Database Syst Rev. 2013;2:CD008994.

96. Dolapcioglu K, Boz A, Baloglu A. The efficacy of intrauterine versus oral progestin for the treatment of endometrial hyperplasia. A prospective randomized comparative study. Clin Exp Obstet Gynecol. 2013;40(1):122-126.

97. Abu Hashim H, Zayed A, Ghayaty E, El Rakhawy M. LNG-IUS treatment of non-atypical endometrial hyperplasia in perimenopausal women: a randomized controlled trial. J Gynecol Oncol. 2013;24(2):128-134.

98. Ismail MT, Fahmy DM, Elshmaa NS. Efficacy of levonorgestrelreleasing intrauterine system versus oral progestins in treatment of simple endometrial hyperplasia without atypia. Reprod Sci. 2013;20(1):45-50.

99. Wong AW, Chan SS, Yeo W, Yu MY, Tam WH. Prophylactic use of levonorgestrel-releasing intrauterine system in women with breast cancer treated with tamoxifen: a randomized controlled trial. Obstet Gynecol. 2013;121(5):943-950.
Patient Preference and Adherence

\section{Publish your work in this journal}

Patient Preference and Adherence is an international, peer-reviewed, open access journal focusing on the growing importance of patient preference and adherence throughout the therapeutic continuum. Patient satisfaction, acceptability, quality of life, compliance, persistence and their role in developing new therapeutic modalities and compounds to

\section{Dovepress}

optimize clinical outcomes for existing disease states are major areas of interest. This journal has been accepted for indexing on PubMed Central. The manuscript management system is completely online and includes a very quick and fair peer-review system. Visit http://www.dovepress.com/ testimonials.php to read real quotes from published authors. 